\title{
19th EURETINA Congress Keynote Lecture: Diabetic Retinopathy Today
}

\author{
Francesco Bandello ${ }^{a, b}$ Maria Vittoria Cicinelli ${ }^{a, b}$

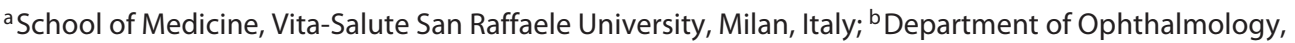 \\ IRCCS San Raffaele Scientific Institute, Milan, Italy
}

\section{Keywords}

Diabetic retinopathy - Diabetic macular edema .

Anti-vascular endothelial growth factor - Optical coherence tomography · Panretinal photocoagulation

\begin{abstract}
In the last decades, significant changes have been taking place regarding the pathogenesis of diabetic retinopathy (DR) and the complex mechanisms that eventually lead to the various manifestations of the disease, including diabetic macular edema (DME). DR was first considered a pure microvascular disease, due to the evident capillary structural changes (microaneurysms), fluid extravasation, and lipid exudation. With the advent of fundus fluorescein angiography, the concept of ischemia and the correlation between peripheral nonperfusion and neovascularization has been introduced, which was eventually followed by the advent of new therapeutic strategies, such as peripheral photocoagulation. Nowadays, thanks to more advanced imaging techniques, namely optical coherence tomography (OCT), OCT angiography, and wide-field imaging (imaging up to $200^{\circ}$ of the retina in a single shot), it became clear that other elements participate in the occurrence of DR and DME, including inflamma-
\end{abstract}

karger@karger.com

www.karger.com/oph

Karger" tion and neurodegeneration. In the future, integration of standard investigations with new diagnostic devices would allow the prompt recognition of DR even before clinical signs of the disease are ophthalmoscopically evident, and the development of personalized treatment for both retinopathy and DME will be available.

(c) 2020 S. Karger AG, Basel

"There is no proof of cause-effect relationship between diabetes and retinal complications" Albrecht von Graefe (1828-1870) openly asserted as early as in the mid-19th century [1]; no longer than a few decades later, Sir Stewart Duke-Elder (1898-1978) referred to diabetic retinopathy (DR) as "one of the major tragedies of ophthalmology in the present generation" [2].

In between, significant changes have been taking place regarding the interpretation of the various manifestations of DR and its more frequent complication, diabetic macular edema (DME). In parallel, substantial technological advances have improved the diagnosis and the treatment of these conditions. The purpose of the present review is to give a historical glimpse of DR perception and a comprehensive timeline of the evolving thoughts on its pathogenesis and management. 


\section{The Prehistory, the History without Testimonies}

Before the construction of modern ophthalmoscopes by Charles Babbage (1791-1871) [3] and Hermann von Helmholtz (1821-1894) [4] and in the absence of histopathologic specimens, no one had made a causative link between retinal changes and diabetic disease. In 1846, Appolinaire Bouchardat (1809-1886) was one of the first physicians who reported the occurrence of visual loss in diabetic patients in the absence of anterior segment changes [5]. Nevertheless, these thoughts were in contrast with the skepticism of Albrecht von Graefe and his disciples, who denied any connection between blindness and the diabetic disease. As von Graefe was considered one of the more important (if not the most important) figures in ophthalmology in the 19th century, his theory had the major credit at that time.

\section{Diabetic Retinitis}

The first in vivo description of retinal involvement in diabetes was achievable only with the technical improvements to ophthalmoscopes made by Eduard Jäger (18181884), who first depicted "roundish," yellowish spots of extravasations in the macula of diabetic patients [6]. In the same years, other illustrious physicians, such as Eugène Bouchut (1818-1891) [7], Henry Noyes (18321900) [8], and Louis-Auguste Desmarres (1810-1882) [9], reported cases of albuminuric retinitis and glycosuric retinitis, respectively, with overlapping retinal and anterior segment findings.

In parallel, Stephen Mackenzie (1844-1909) and Edward Nettleship (1845-1913) presented the first histopathologic evidence of diabetes-related changes in 1877, describing microaneurysms and basement membrane thickening of the retinal capillaries and cystoid degeneration of the macula [10]. Although they concluded that "the perivascular [retinal] hemorrhages, extrusions, excavations, and atrophies" were the consequences and not the causes of diabetes [11], they still interpreted these signs as resulting from local inflammation, in a general picture of retinitis.

\section{Diabetic Microangiopathy}

It was only at the beginning of the 19th century that James Ballantyne (1876-1954) and Arnold Loewenstein (1882-1952) rejected the misnomer "retinitis" in favor of
Table 1. The O'Hare Classification of diabetic retinopathy

\begin{tabular}{|c|c|}
\hline Class & Description \\
\hline $\mathrm{B}_{1}-\mathrm{B}_{4}$ & $\begin{array}{l}\text { Background retinopathy, including microaneurysms, } \\
\text { blotch hemorrhages, exudates, and venous abnormalities } \\
\text { in increasing severity; no signs of new vessels or fibrous } \\
\text { proliferation }\end{array}$ \\
\hline $\mathrm{N}_{0}$ & Absence of new vessels \\
\hline $\mathrm{N}_{1}$ & $\begin{array}{l}\text { Four or fewer discreet patches or } 4 \text { or fewer disc areas of } \\
\text { new vessels }\end{array}$ \\
\hline $\mathrm{N}_{2}$ & $\begin{array}{l}\text { Greater than } 4 \text { discreet patches or greater than } 4 \text { disc } \\
\text { areas of new vessels }\end{array}$ \\
\hline $\mathrm{H}_{0}$ & No vitreous hemorrhage \\
\hline $\mathrm{H}_{1}$ & $\begin{array}{l}\text { Presence of vitreous or preretinal hemorrhage but the } \\
\text { retina can be seen well enough to be classified }\end{array}$ \\
\hline $\mathrm{H}_{2}$ & $\begin{array}{l}\text { Vitreous hemorrhage so extensive that the retina cannot } \\
\text { be seen well enough to be classified }\end{array}$ \\
\hline $\mathrm{F}_{0}$ & $\begin{array}{l}\text { No fibrous proliferation extending into the vitreous } \\
\text { cavity }\end{array}$ \\
\hline $\mathrm{F}_{1}$ & $\begin{array}{l}\text { Fibrous proliferation extending into the vitreous cavity } \\
\text { but involving } 4 \text { or fewer discreet patches or } 4 \text { or fewer } \\
\text { disc areas }\end{array}$ \\
\hline $\mathrm{F}_{2}$ & $\begin{array}{l}\text { Greater than } 4 \text { discreet patches or greater than } 4 \text { disk } \\
\text { areas of fibrous proliferation extending into the vitreous }\end{array}$ \\
\hline
\end{tabular}

the eponym "diabetic retinopathy," interpreting DR as a pure vascular disease, in which the retinal lesions derived from a primary damage of the capillary endothelium [12]. With the advent of fundus fluorescein angiography (FFA) in 1961 by Harold R. Novotny and David L. Alvis [13], novel concepts, such as peripheral nonperfusion and blood-retinal barrier breakdown, were introduced, which eventually paved the way for new therapeutic strategies, such as peripheral photocoagulation.

Daniel J. Scott in 1964 [14], Edward W.D. Norton in 1965 [15], and Donald Gass in 1967 [16] made their greatest contribution to the depiction of epiretinal, dye-leaking, convoluted fibrovascular tissue characterizing the most advanced form of DR, namely proliferative DR (PDR). FFA made it possible to visualize, describe, and quantify the microvascular alterations in diabetic eyes and their changes with time; the very close relationship between hemorheological alterations, retinal ischemia, and PDR was undoubtedly elucidated. While in Japan the group of Koichi Shimizu correlated the presence of neovascularization with the extent of peripheral capillary nonperfusion 

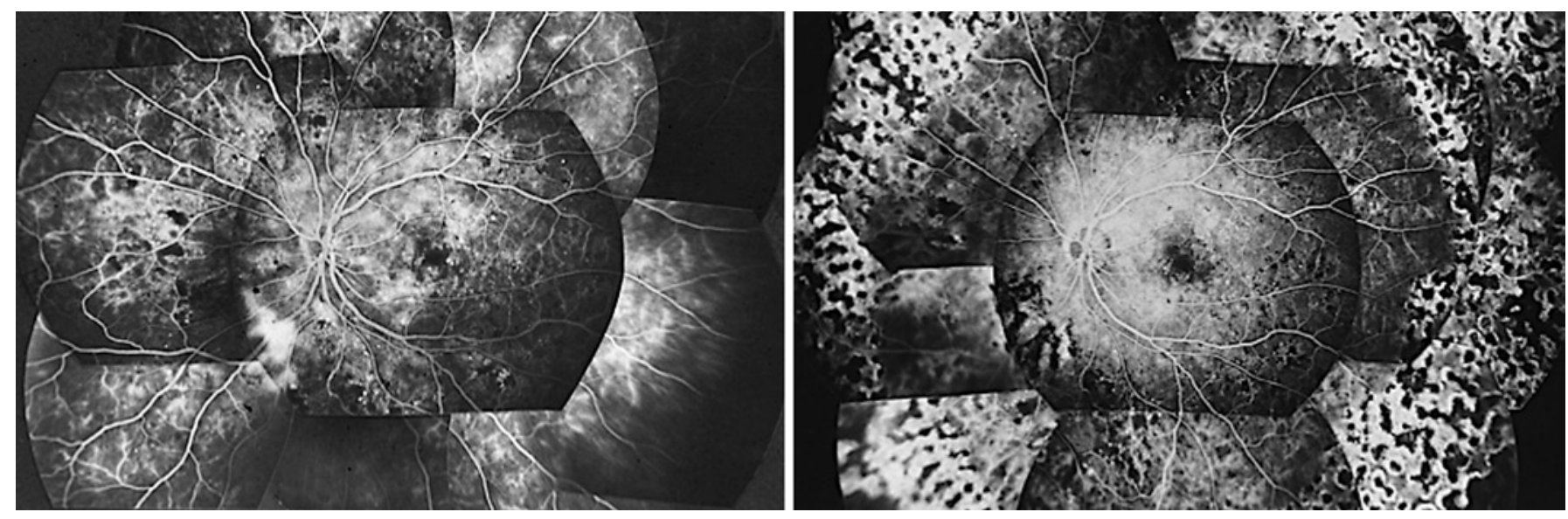

Fig. 1. A patient with proliferative diabetic retinopathy before and after "targeted" panretinal photocoagulation. Left: Fundus fluorescein angiography, showing diffuse breakdown of the blood-retinal barrier, macular ischemia, capillary nonperfusion on $360^{\circ}$, and epiretinal neovascularization along the inferior nasal vascular branches. Right: Fundus fluorescein angiography of the same patient after a "targeted" panretinal photocoagulation, aimed to destroy only the nonperfused retina. The neovascularization successfully regressed after laser treatment.

$[17,18]$, different scientists started postulating the existence of a neovascular factor responsible for diabetes-related ocular changes [19]. The "pioneers of angiogenesis," i.e., Judah Folkman [20], Harold Dvorak [21], and Napoleone Ferrara [22], eventually headed to the discovery of vascular endothelial growth factor (VEGF) a few years later.

Novel entities secondary to diabetic microangiopathy, namely diabetic papillopathy [23] and diabetic iridopathy [24], were introduced thanks to FFA and anterior-segment fluorescein angiography, respectively. Diabetic iridopathy turned out to be a valuable predictor of the severity of retinopathy, particularly useful in patients with scarce dilation, opaque ocular media, and poor compliance [25].

The shift from the traditional fundus camera to digital systems based on confocal scanning laser ophthalmoscopes, capable of major spatial resolution and pixel definition compared to film-based angiography, consistently helped in depicting the retinal vascular impairment in diabetic eyes [26]. Twenty years later, other innovations would have given unexpected insights into DR microangiopathy, both in the macula and in the very-far periphery; but first things first, some more steps were needed before coming to this.

\section{DR Classification and Laser Photocoagulation}

The identification of the different phenotypes of DR, each with its own natural history and visual prognosis, raised the need for a universal classification of the disease.
A plethora of medical and surgical attempts of treatment was emerging, each with controversial scientific consistency or efficacy. At that time, pituitary ablation was dangerously starting to be a diffuse practice $[27,28]$. In parallel, the first model of high-pressure Xenon laser was developed by Zeiss, thanks to the pioneering work of Gerhard Meyer-Schwickerath (1920-1992) [29]. Xenon laser was then replaced by ruby laser [30] and argon laser photocoagulation [31] a few years later. While there was general agreement on the focal treatment technique directed at the areas of visible neovascularization, the concept of an indirect favorable effect of "spray" or "scatter" photocoagulation on areas of nonperfusion to induce regression of neovascularization was still unexplored [32, 33].

In the attempt to find a remedy for this heterogeneity, a rural, bucolic site (The Airlie House, Virginia) was chosen as the setting for the first expert consensus on DR among epidemiologists, neurosurgeons, internists, and ophthalmologists. The Airlie House Symposium was a summary of the available knowledge on DR, from the pathogenesis to diagnosis and management, setting the ground for the design of the upcoming major clinical trials. A preliminary classification of DR was distributed among participants before the meeting (Table 1) [34] and then reorganized into 13 complex stages, from level 10 (absence of retinopathy) to level 85 (severe vitreous hemorrhage or retinal detachment involving the macula).

One of the major novelties of the Airlie House Classification was the usage of stereo-photograph montage 


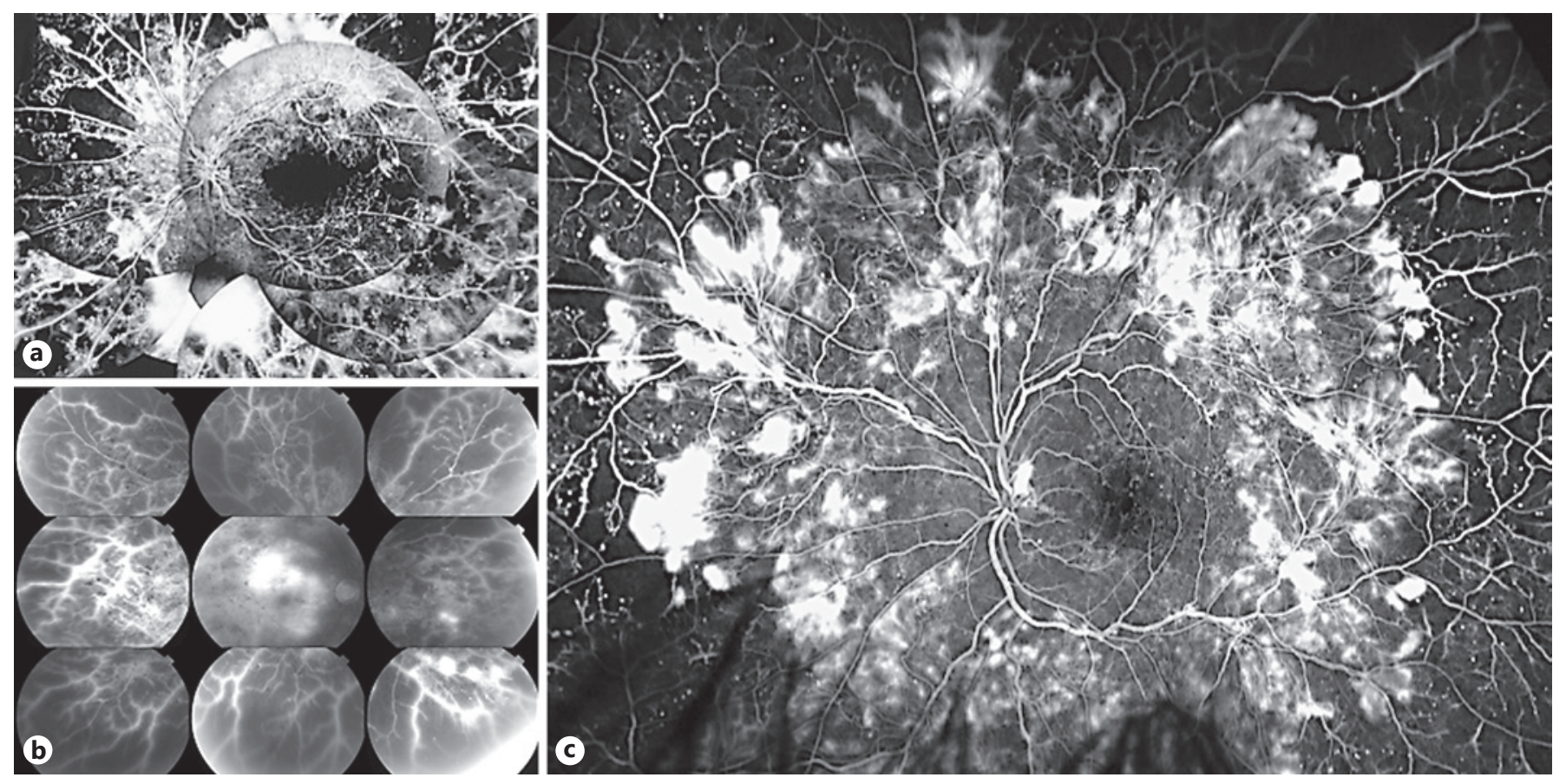

Fig. 2. Evolution of widefield reconstruction of fundus fluorescein angiography in proliferative diabetic retinopathy. a Fundus camera film-based pictures of the central $50^{\circ}$ with a manual widefield reconstruction. $\mathbf{b}$ Fundus camera digital pictures of the central $50^{\circ}$ with an automatic widefield reconstruction (Topcon Trc-50Dx Retinal Camera). c Ultra-widefield photography (Optos California, Dunfermline, Scotland, UK) capturing up to $200^{\circ}$ in a single shot.

covering 7 standard photographic fields for DR grading, which allowed reproducibility and standardization of image acquisition. Slightly modified by the Early Treatment of Diabetic Retinopathy Study (ETDRS), this classification became the gold standard in the research setting. It was validated in large prospective, multicenter, randomized clinical trials, including the Diabetic Retinopathy Study (DRS) [35], the ETDRS [36, 37], the Diabetic Retinopathy Vitrectomy Study (DRVS) [38], and the Krypton-Argon Regression of Neovascularization Study (KARNS) [39]. These studies represented landmarks in the 20th-century ophthalmology, providing worldwide guidelines on the use of laser panretinal photocoagulation (PRP) and focal laser for the different stages of DR.

To reduce the burden of complications held by conventional laser therapy [40, 41], new laser methodologies and novel techniques of application soon developed [42]. Our group demonstrated how "lighter" argon laser, leaving a less whitening biomicroscopic effect on the retina, was associated with similar efficacy and minor discomfort compared with conventional high-energy argon green output (Fig. 1) [43, 44].
Other types of lasers than argon green $(352 \mathrm{~nm})$, including orange dye $(600 \mathrm{~nm})$ laser [45], red $(630 \mathrm{~nm})$ and yellow $(580 \mathrm{~nm})$ dye lasers [46], diode ( $810 \mathrm{~nm})$ laser [47], and double-frequency Nd:YAG laser $(532 \mathrm{~nm})$ [48], were proved to have an efficiency similar to conventional PRP. Conversely, physics and physicians made their best to develop "nondamaging" devices, capable to deliver selective laser treatment to the retinal pigment epithelium, sparing the neurosensory retina [49]. Micropulse diode laser, based on a train of millisecond laser pulses in a very short duty cycle, and "subthreshold" laser delivery, i.e., the treatment of the retina without leaving any detectable sign at any retinal imaging modality, are outstanding examples of "nondamaging" techniques [50,51].

The scenario of laser photocoagulation is dynamically evolving at the present time, thanks to the breakthrough innovations in diagnostic technology and DR pharmacology. On the one hand, widefield FFA and ultra-widefield FFA, allowing for imaging of the peripheral retina up to $200^{\circ}$ [52], have become invaluable tools for guiding laser treatment in a targeted or planned approach, aiming to obliterate only the ischemic retina responsible for the proangiogenic drive (Fig. 2) $[53,54]$. On the other hand, 
the Protocol S by the DRCR.net $[55,56]$ and the PROTEUS study [57] have opened the door on alternative medical treatments for PDR, albeit requiring greater compliance and economical costs compared to traditional PRP. Upcoming trials with longer follow-up and multiethnic cohorts will better clarify the role of laser photocoagulation in DR and its combination with anti-VEGF treatments [56].

\section{Diabetic Maculopathy}

Along with focusing on DR, the ETDRS proposed the first description of a peculiar subtype of DME, known as clinically significant macular edema, and defined it upon precise slit-lamp biomicroscopy findings [58]. At that time, 2 concepts were privileged in the interpretation of DME: pure microvascular pathogenesis and a strict correlation between retinal thickening and the functional outcome [59].

Since the introduction of optical coherence tomography (OCT) in 1991 as a new, noninvasive method of macula imaging [60], further insights into the morphology and features of DME were easily available to the ophthalmic practitioners. Structural OCT was able to surprisingly document retinal thickness, cystic maculopathy, exudates, hyperreflective foci, the state of the inner retinal architecture, as well as the external limiting membrane and the ellipsoid zone, the integrity of the retinal pigment epithelium, and the presence of subretinal fluid for the first time.

With its support, new attempts to classify DME based not only on the location of the retinal thickening [61], but also on additional features associated with differing severities, response to treatment, and visual prognosis were proposed; the distinction into these subtypes used to have major importance in the treatment algorithm before the advent of anti-VEGF agents $[62,63]$. The first major distinction was into focal and diffuse DME subtypes [64]. According to its nature, DME was also classified into "vasogenic" or "retinovascular," indicating the origin of thickening from discrete microvascular leaking alterations in the macular region, and "nonvasogenic," caused by a general breakdown of the inner blood-retinal barrier $[65,66]$. A third subtype, named "tractional," was acknowledged for its main surgical interest.

Thanks to the shift from time-domain models to spectral-domain and swept-source devices, it became clear that other elements participate in the occurrence of diabetes-related macular damage. A paradigm shift in DME interpretation from pure microangiopathy to neurovas-

Diabetic Retinopathy Today
Table 2. Staging of DM according to the European School for Advanced Studies in Ophthalmology (ESASO) classification

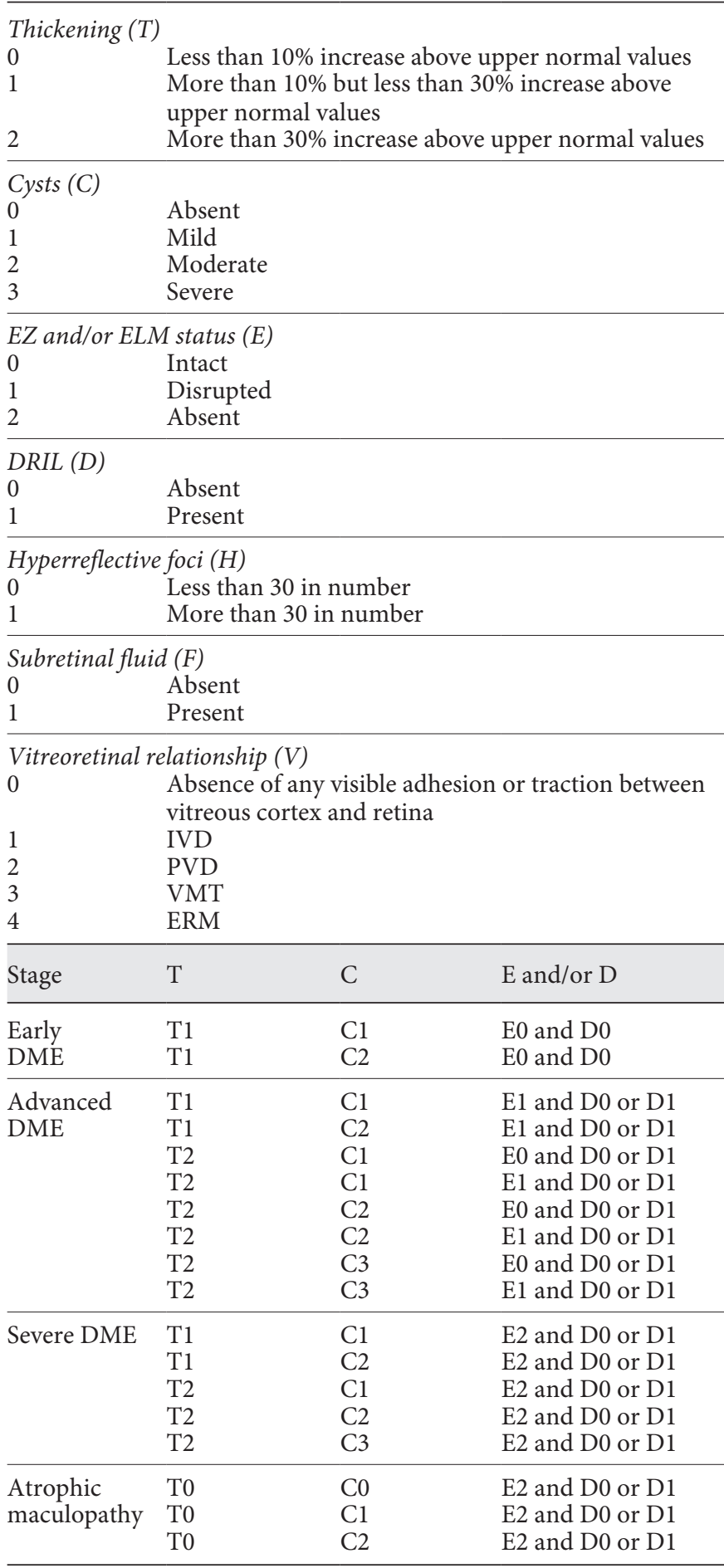

Adapted from Panozzo et al. [73]. DM, diabetic maculopathy; EZ, ellipsoid zone; ELM, external limiting membrane; DRIL, disorganization of the inner retinal layers; IVD, incomplete posterior vitreous detachment; PVD, complete posterior vitreous detachment; VMT, vitreomacular traction; ERM, epiretinal membrane; DME, diabetic macular edema. 
cular coupling dysfunction took place, as ganglion, horizontal, Müller, and amacrine retinal cells and photoreceptors appeared to be morphologically and functionally impaired even before the first ophthalmoscopically detectable signs of DR [67-69]. Chronic local inflammation has been recognized as a critical factor in DME pathogenesis [70], and OCT has contributed to providing indirect inflammatory biomarkers, namely subfoveal neuroretinal detachment and hyperreflective retinal spots/foci, since the very first stages of macular involvement $[71,72]$.

In the attempts to comprehensively merge these novel thoughts, an international panel of experts from the European School for Advanced Studies in Ophthalmology (ESASO) has proposed a morphologic classification of DME. It has been intentionally designed to address all forms of macular involvement in DR, including those not presenting macular thickening as a primary feature (Table 2) [73].

\section{Evolution of DR and DME Treatment}

The increasing understanding of the pathogenesis of DR and DME has had crucial consequences on the therapeutic approaches. Laser photocoagulation has been considered the standard of care for both DR and DME for decades.

The discovery of intravitreal VEGF antagonists represents one of the most significant healthcare breakthroughs achieved in ophthalmology. Soon after the very first pieces of evidence of the efficacy of monthly bevacizumab in DME [74, 75], new molecules (i.e., ranibizumab and aflibercept) and new treatment regimens (pro-re-nata and treat-and-extend) have blossomed to improve the benefits of the antiangiogenic agents [76]. Besides anti-VEGF, the introduction of intravitreal corticosteroids and sustainedrelease drug delivery systems have been additional powerful tools in the DME treatment armamentarium [77].

Nevertheless, diverse issues must be resolved to optimize the current practice and represent undeniable challenges for the next years. Both anti-VEGF agents and corticosteroids are highly effective for the treatment of DME; however, there is still a proportion of patients who achieve a suboptimal response to medical treatment. Moreover, current drug formulations have a relatively short duration of action (from 4 to 8 weeks for anti-VEGF and 4 months for dexamethasone implant) and a considerably high rate of DME recurrence after discontinuation.

Long-lasting, next-generation anti-VEGF agents and steroidal implants have been under investigation for reducing the burden of DME treatment. Brolucizumab
(RTH258, Alcon, Fort Worth, TX, USA), which is expected to last 12 weeks, has just been approved for neovascular age-related macular degeneration and is currently tested for DME in a phase III randomized clinical trial [78]. At the same time, a 190- $\mu$ g fluocinolone acetonide nonbioerodable implant (Iluvien $^{\circledR}$, Alimera Sciences, Inc., Alpharetta, GA, USA), which has a theoretical efficacy up to 36 months, has been licensed in the United States and Europe to treat DME insufficiently responsive to previous available therapies.

Novel technologies, new therapeutic targets addressing different steps in the angiogenesis cascade, and innovative routes of administration must be explored to overcome the limitations of the present alternatives. There are great expectations on the port delivery system, a permanent, refillable implant that is surgically inserted through the pars plana, which can continuously release ranibizumab into the vitreous cavity [79]. On the other hand, specific antibodies targeting angiopoietin-2 have proven promising effects coupled with intravitreal anti-VEGF in the treatment of DME [80]. Lastly, suprachoroidal space delivery, which has the advantage to achieve the same therapeutic drug levels in the retina as compared to intravitreal injections but minimizing the drug levels in the anterior segment, has shown encouraging feasibility and safety in phase I/II clinical trials [81].

\section{Final Remarks and Future Perspectives}

In my career, I have witnessed an authentic revolution in the management of patients with DR. The progresses with imaging technology, laser treatment, and intravitreal pharmacologic agents, such as anti-VEGF and corticosteroid implants, have improved dramatically the visual prognosis of diabetic patients. The future investigations will go towards the possibility to recognize signs of DR in advance to their clinical manifestation, allowing for more effective prevention strategies and timely treatments. In this view, OCT angiography, able to visualize the distributional characteristics of vascular alterations even in diabetics with no apparent DR $[82,83]$, might have a pivotal role in the future screening programs of DR. The integration of standard investigations with novel diagnostic techniques will allow the development of personalized treatment for both retinopathy and DME based on the individual disease features. Finally, the upcoming changes in the treatment paradigm for DR and DME are extremely exciting. We have nowadays a promising picture of what we will expect from DR tomorrow. 


\section{Statement of Ethics}

The research did not involve any human or animal subjects.

\section{Funding Sources}

This research did not receive any specific grant from funding agencies in the public, commercial, or not-for-profit sectors.

\section{Disclosure Statement}

M.V.C. has no financial disclosure. F.B. is consultant for Alcon (Fort Worth, TX, USA), Alimera Sciences (Alpharetta, GA, USA), Allergan Inc. (Irvine, CA, USA), Farmila-Théa (Clermont-Ferrand, France), Bayer Schering Pharma (Berlin, Germany), Bausch and Lomb (Rochester, NY, USA), Genentech (San Francisco, CA, USA), Hoffmann-La-Roche (Basel, Switzerland), Novagali Pharma (Évry, France), Novartis (Basel, Switzerland), Sanofi-Aventis (Paris, France), Thrombogenics (Heverlee, Belgium), and Zeiss (Dublin, CA, USA).

\section{Author Contributions}

M.V.C. and F.B. contributed to the conception or design of the work, the acquisition of data, drafting the work, revising it critically for important intellectual content, and gave final approval for the version to be published.

\section{References}

1 Von Graefe A. Ueber die mit Diabetes mellitus vorkommenden Sehstörungen. Dies Arch. 1958;IV:230-4.

2 Duke-Elder S. System of Ophthalmology. Volume 10. St Louis: CV Mosby Co; 1967.

3 Keeler CR. 150 years since Babbage's ophthalmoscope. Arch Ophthalmol. 1997 Nov; 115(11):1456-7.

4 Keeler CR. The ophthalmoscope in the lifetime of Hermann von Helmholtz. Arch Ophthalmol. 2002 Feb;120(2):194-201.

5 Bouchardat A. Nouveau mémoire sur la glycosurie. Ann de Thérap Suppl. 1846:162-311.

6 Jaeger Ritter von Jaxtthal E. Beiträge zur Pathologie des Auges. Wiss. SbA; 1955.

7 Bouchut E. Du Diagnostic Des Maladies Du Systeme Nerveux Par L'Ophthalmoscopie. 1866.

8 Noyes HD. Retinitis in Glycosuria. Trans Am Ophthalmol Soc. 1868;1(4-5):71-5.

9 Desmarres LA. Traite théorique et pratique des maladies des yeux. 1847.

10 Nettleship E. On oedema or cystic disease of the retina. Ophth Hosp Rep. 1872;7(3):34351.

11 Mackenzie S, Nettleship E. A case of glycosuric retinitis. Ophth Hosp Rep. 1877;9:134.

12 Ballantyne AJ, Loewenstein A. Retinal MicroAneurysms and Punctate Haemorrhages. Br J Ophthalmol. 1944 Dec;28(12):593-8.

13 Novotny HR, Alvis DL. A method of photographing fluorescence in circulating blood in the human retina. Circulation. 1961 Jul;24(1): 82-6.

14 Scott DJ, Dollery CT, Hill DW, Hodge JV, Fraser R. Fluorescein Studies of Diabetic Retinopathy. BMJ. 1964 Mar;1(5386):811-4.

15 Norton EW, Gutman F. Diabetic retinopathy studied by fluorescein angiography. Ophthalmologica. 1965;150(1):5-17.

16 Gass JD, Sever RJ, Sparks D, Goren J. A combined technique of fluorescein funduscopy and angiography of the eye. Arch Ophthalmol. 1967 Oct; 78(4):455-61.
17 Shimizu K, Kobayashi Y, Muraoka K. Midperipheral fundus involvement in diabetic retinopathy. Ophthalmology. $1981 \mathrm{Jul} ; 88(7)$ : 601-12.

18 Niki T, Muraoka K, Shimizu K. Distribution of capillary nonperfusion in early-stage diabetic retinopathy. Ophthalmology. $1984 \mathrm{Dec}$; 91(12):1431-9.

19 Bandello F, Gass JD, Lattanzio R, Brancato R Spontaneous regression of neovascularization at the disk and elsewhere in diabetic retinopathy. Am J Ophthalmol. 1996 Oct;122(4): 494-501.

20 Folkman J. Tumor angiogenesis: therapeutic implications. N Engl J Med. 1971 Nov: 285(21):1182-6.

21 Senger DR, Perruzzi CA, Feder J, Dvorak HF. A highly conserved vascular permeability factor secreted by a variety of human and rodent tumor cell lines. Cancer Res. 1986 Nov; 46(11):5629-32.

22 Leung DW, Cachianes G, Kuang WJ, Goeddel DV, Ferrara N. Vascular endothelial growth factor is a secreted angiogenic mitogen. Science. 1989 Dec;246(4935):1306-9.

23 Brancato R, Menchini U, Bandello FM. Diabetic papillopathy: fluorangiographic aspects. Metab Pediatr Syst Ophthalmol (1985). 1986; 9(2-4):57-61.

24 Bandello F, Brancato R, Lattanzio R, Falcomatà $\mathrm{B}$, Malegori A. Biomicroscopy versus fluorescein angiography of the iris in the detection of diabetic iridopathy. Graefes Arch Clin Exp Ophthalmol. 1993 Aug;231(8):4448.

25 Bandello F, Brancato R, Lattanzio R, Galdini $\mathrm{M}$, Falcomatà $\mathrm{B}$. Relation between iridopathy and retinopathy in diabetes. $\mathrm{Br} \mathrm{J}$ Ophthalmol. 1994 Jul;78(7):542-5.

26 Wolf S, Arend O, Toonen H, Bertram B, Jung F, Reim M. Retinal capillary blood flow measurement with a scanning laser ophthalmoscope. Preliminary results. Ophthalmology. 1991 Jun;98(6):996-1000.
27 Speakman JS, Mortimer CB, Briant TD, Ezrin C, Lougheed WM, Clarke WT. Pituitary ablation for diabetic retinopathy. Can Med Assoc J. 1966 Mar;94(13):627-35.

28 Joplin GF, Fraser R, Hill DW, Oakley NW, Scott DJ, Doyle. Pituitary ablation for diabetic retinopathy. Q J Med. 1965 Oct;34(136): $443-62$.

29 Meyer-Schwickerath G. [Light coagulation]. Ber Zusammenkunft Dtsch Ophthalmol Ges. 1965;66:313-25.

30 Beetham WP, Aiello LM, Balodimos MC, Koncz L. Ruby-laser photocoagulation of early diabetic neovascular retinopathy: preliminary report of a long-term controlled study. Trans Am Ophthalmol Soc. 1969;67:39-67.

31 Zweng HC, Little HL, Peabody RR. Further observations on argon laser photocoagulation of diabetic retinopathy. Trans Am Acad Ophthalmol Otolaryngol. 1972 Jul-Aug;76(4): 990-1004.

32 Okun E. Summary of papers on treatment techniques in photocoagulation. In: Goldberg M, Fine SL, editors. Symposium on the Treatment of Diabetic Retinopathy. Washington, DC: US Department of Health, Education and Welfare; 1969.

33 Goldberg MF, Jampol LM. Knowledge of diabetic retinopathy before and 18 years after the Airlie House Symposium on Treatment of Diabetic Retinopathy. Ophthalmology. 1987 Jul;94(7):741-6.

34 Davis MD, Fine SL, Goldberg MF, McMeel JW, Norton EWD, Okun E, et al. O'Hare Classification of diabetic retinopathy. In: Goldberg MF, Fine SL, editors. Symposium on the Treatment of Diabetic Retinopathy. Washington, DC: US Department of Health, Education and Welfare; 1969.

35 Patz A, Fine S, Finkelstein D, Prout T, Aiello L, Bradley R, et al. Photocoagulation treatment of proliferative diabetic retinopathy: the second report of diabetic retinopathy study findings. Ophthalmology. 1978 Jan;85(1):82-106. 
36 Diabetic retinopathy study. Report Number 6. Design, methods, and baseline results. Report Number 7. A modification of the Airlie House classification of diabetic retinopathy. Prepared by the Diabetic Retinopathy. Invest Ophthalmol Vis Sci. 1981 Jul;21(1 Pt 2):1226.

37 Early Treatment Diabetic Retinopathy Study Research Group. Treatment techniques and clinical guidelines for photocoagulation of diabetic macular edema. Early Treatment Diabetic Retinopathy Study Report Number 2 . Ophthalmology. 1987 Jul;94(7):761-74.

38 Two-year course of visual acuity in severe proliferative diabetic retinopathy with conventional management. Diabetic Retinopathy Vitrectomy Study (DRVS) report \#1. Ophthalmology. 1985 Apr;92(4):492-502.

39 Singerman LJ, Ferris FL 3rd, Mowery RP, Brucker AJ, Murphy RP, Lerner BC, et al. Krypton laser for proliferative diabetic retinopathy: the Krypton Argon Regression of Neovascularization Study. J Diabet Complications. 1988 Oct-Dec;2(4):189-96.

40 Frank RN. Visual fields and electroretinography following extensive photocoagulation. Arch Ophthalmol. 1975 Aug;93(8):591-8.

41 Morgan CM, Schatz H. Atrophic creep of the retinal pigment epithelium after focal macular photocoagulation. Ophthalmology. 1989 Jan;96(1):96-103.

42 Brancato R, Bandello F. New laser modalities for posterior segment treatment. Curr Opin Ophthalmol. 1991 Jun;2(3):299-305.

43 Bandello F, Brancato R, Menchini U, Virgili G, Lanzetta P, Ferrari E, et al. Light panretinal photocoagulation (LPRP) versus classic panretinal photocoagulation (CPRP) in proliferative diabetic retinopathy. Semin Ophthalmol. 2001 Mar; 16(1):12-8.

44 Bandello F, Polito A, Del Borrello M, Zemella N, Isola M. "Light" versus "classic" laser treatment for clinically significant diabetic macular oedema. Br J Ophthalmol. 2005 Jul;89(7): 864-70.

45 Seiberth V, Schatanek S, Alexandridis E. Panretinal photocoagulation in diabetic retinopathy: argon versus dye laser coagulation. Graefes Arch Clin Exp Ophthalmol. 1993 Jun; 231(6):318-22.

46 Atmaca LS, Idil A, Gündüz K. Dye laser treatment in proliferative diabetic retinopathy and maculopathy. Acta Ophthalmol Scand. 1995 Aug;73(4):303-7.

47 Bandello F, Brancato R, Trabucchi G, Lattanzio R, Malegori A. Diode versus argon-green laser panretinal photocoagulation in proliferative diabetic retinopathy: a randomized study in 44 eyes with a long follow-up time. Graefes Arch Clin Exp Ophthalmol. 1993 Sep; 231(9):491-4

48 Bandello F, Brancato R, Lattanzio R, Trabucchi G, Azzolini C, Malegori A. Double-frequency Nd:YAG laser vs. argon-green laser in the treatment of proliferative diabetic retinopathy: randomized study with long-term follow-up. Lasers Surg Med. 1996;19(2):173-6.
49 Rebeiz EE, Aretz HT, Shapshay SM, Pankratov MM. Application of pulsed and continuous wave 1.32 and 1.06 microns wavelengths of the Nd:YAG laser in the canine tracheobronchial tree: a comparative study. Lasers Surg Med. 1990;10(6):501-9.

50 Luttrull JK, Dorin G. Subthreshold diode micropulse laser photocoagulation (SDM) as invisible retinal phototherapy for diabetic macular edema: a review. Curr Diabetes Rev. 2012 Jul;8(4):274-84.

51 Kozak I, Luttrull JK. Modern retinal laser therapy. Saudi J Ophthalmol. 2015 Apr-Jun; 29(2):137-46

52 Cicinelli MV, Cavalleri M, Brambati M, Lattanzio R, Bandello F. New imaging systems in diabetic retinopathy. Acta Diabetol. 2019 Sep; 56(9):981-94

53 Nikkhah H, Ghazi H, Razzaghi MR, Karimi S, Ramezani A, Soheilian M. Extended targeted retinal photocoagulation versus conventional pan-retinal photocoagulation for proliferative diabetic retinopathy in a randomized clinical trial. Int Ophthalmol. 2018 Feb;38(1): 313-21.

54 Muqit MM, Young LB, McKenzie R, John B, Marcellino GR, Henson DB, et al. Pilot randomised clinical trial of Pascal TargETEd Retinal versus variable fluence PANretinal $20 \mathrm{~ms}$ laser in diabetic retinopathy: PETER PAN study. Br J Ophthalmol. 2013 Feb;97(2):220-

55 Gross JG, Glassman AR, Jampol LM, Inusah S, Aiello LP, Antoszyk AN, et al.; Writing Committee for the Diabetic Retinopathy Clinical Research Network. Panretinal Photocoagulation vs Intravitreous Ranibizumab for Proliferative Diabetic Retinopathy: A Randomized Clinical Trial. JAMA. 2015 Nov; 314(20):2137-46.

56 Sun JK, Glassman AR, Beaulieu WT, Stockdale CR, Bressler NM, Flaxel C, et al.; Diabetic Retinopathy Clinical Research Network. Rationale and Application of the Protocol S Anti-Vascular Endothelial Growth Factor Algorithm for Proliferative Diabetic Retinopathy. Ophthalmology. 2019 Jan;126(1):87-95.

57 Figueira J, Fletcher E, Massin P, Silva R, Bandello F, Midena E, et al.; EVICR.net Study Group. Ranibizumab Plus Panretinal Photocoagulation versus Panretinal Photocoagulation Alone for High-Risk Proliferative Diabetic Retinopathy (PROTEUS Study). Ophthalmology. 2018 May;125(5):691-700.

58 Early Treatment Diabetic Retinopathy Study Research Group. Grading diabetic retinopathy from stereoscopic color fundus photographs-an extension of the modified Airlie House classification. ETDRS report number 10. Ophthalmology. 1991 May;98(5 Suppl): 786-806.

59 Deák GG, Schmidt-Erfurth UM, Jampol LM. Correlation of Central Retinal Thickness and Visual Acuity in Diabetic Macular Edema. JAMA Ophthalmol. 2018 Nov;136(11):12156.
60 Huang D, Swanson EA, Lin CP, Schuman JS, Stinson WG, Chang W, et al. Optical coherence tomography. Science. 1991 Nov; 254(5035):1178-81.

61 Scott IU, Danis RP, Bressler SB, Bressler NM, Browning DJ, Qin H; Diabetic Retinopathy Clinical Research Network. Effect of focal/ grid photocoagulation on visual acuity and retinal thickening in eyes with non-centerinvolved diabetic macular edema. Retina. 2009 May;29(5):613-7.

62 Bandello F. Fluorescein angiography in laser treatment of diabetic macular edema. Ophthalmology. 2001 Feb;108(2):236.

63 Bandello F, Lanzetta P, Menchini U. When and how to do a grid laser for diabetic macular edema. Doc Ophthalmol. 1999;97(3-4):415-9.

64 Browning DJ, Altaweel MM, Bressler NM, Bressler SB, Scott IU; Diabetic Retionpathy Clinical Research Network. Diabetic macular edema: what is focal and what is diffuse? Am J Ophthalmol. 2008 Nov;146(5):649-55, 655. e1-6.

65 Bandello F, Pognuz R, Polito A, Pirracchio A, Menchini F, Ambesi M. Diabetic macular edema: classification, medical and laser therapy. Semin Ophthalmol. 2003 Dec;18(4):251-8.

66 Parodi Battaglia M, Iacono P, Cascavilla M, Zucchiatti I, Bandello F. A Pathogenetic Classification of Diabetic Macular Edema. Ophthalmic Res. 2018;60(1):23-8.

67 Pierro L, Iuliano L, Cicinelli MV, Casalino G Bandello F. Retinal neurovascular changes appear earlier in type 2 diabetic patients. Eur J Ophthalmol. 2017 May;27(3):346-51.

68 Gardner TW, Davila JR. The neurovascular unit and the pathophysiologic basis of diabetic retinopathy. Graefes Arch Clin Exp Ophthalmol. 2017 Jan;255(1):1-6.

69 Das A, McGuire PG, Rangasamy S. Diabetic Macular Edema: Pathophysiology and Novel Therapeutic Targets. Ophthalmology. 2015 Jul;122(7):1375-94.

70 Vujosevic S, Muraca A, Alkabes M, Villani E, Cavarzeran F, Rossetti L, et al. Early Microvascular and Neural Changes in Patients with Type 1 and Type 2 Diabetes Mellitus without Clinical Signs of Diabetic Retinopathy. Retina. 2019 Mar;39(3):435-45.

71 Vujosevic S, Bini S, Midena G, Berton M, Pilotto E, Midena E. Hyperreflective intraretinal spots in diabetics without and with nonproliferative diabetic retinopathy: an in vivo study using spectral domain OCT. J Diabetes Res. 2013;2013:491835.

72 Vujosevic S, Simó R. Local and Systemic Inflammatory Biomarkers of Diabetic Retinopathy: An Integrative Approach. Invest Ophthalmol Vis Sci. 2017 May;58(6):BIO68-75.

73 Panozzo G, Cicinelli MV, Augustin AJ, Battaglia Parodi M, Cunha-Vaz J, Guarnaccia G, et al. An optical coherence tomography-based grading of diabetic maculopathy proposed by an international expert panel: The European School for Advanced Studies in Ophthalmology classification. Eur J Ophthalmol. 2020 Jan;30(1):8-18 
74 Wu L, Martínez-Castellanos MA, Quiroz-Mercado H, Arevalo JF, Berrocal MH, Farah ME, et al.; Pan American Collaborative Retina Group (PACORES). Twelve-month safety of intravitreal injections of bevacizumab (Avastin): results of the Pan-American Collaborative Retina Study Group (PACORES). Graefes Arch Clin Exp Ophthalmol. 2008 Jan;246(1):81-7.

75 Arevalo JF, Sanchez JG, Fromow-Guerra J, Wu L, Berrocal MH, Farah ME, et al.; PanAmerican Collaborative Retina Study Group (PACORES). Comparison of two doses of primary intravitreal bevacizumab (Avastin) for diffuse diabetic macular edema: results from the Pan-American Collaborative Retina Study Group (PACORES) at 12-month follow-up. Graefes Arch Clin Exp Ophthalmol. 2009 Jun;247(6):735-43.

76 Bandello F, Cicinelli MV, Parodi MB. AntiVEGF Molecules for the Management of Diabetic Macular Edema. Curr Pharm Des. 2015; 21(32):4731-7.
77 Lattanzio R, Cicinelli MV, Bandello F. Intravitreal Steroids in Diabetic Macular Edema. Dev Ophthalmol. 2017;60:78-90.

78 Dugel PU, Koh A, Ogura Y, Jaffe GJ, SchmidtErfurth U, Brown DM, et al. HAWK and HARRIER: Phase 3, Multicenter, Randomized, Double-Masked Trials of Brolucizumab for Neovascular Age-Related Macular Degeneration. Ophthalmology. 2020 Jan;127(1):7284.

79 Campochiaro PA, Marcus DM, Awh CC, Regillo C, Adamis AP, Bantseev V, et al. The Port Delivery System with Ranibizumab for Neovascular Age-Related Macular Degeneration: Results from the Randomized Phase 2 Ladder Clinical Trial. Ophthalmology. 2019 Aug; 126(8):1141-54.

80 Sahni J, Patel SS, Dugel PU, Khanani AM, Jhaveri CD, Wykoff CC, et al. Simultaneous Inhibition of Angiopoietin-2 and Vascular Endothelial Growth Factor-A with Faricimab in Diabetic Macular Edema: BOULEVARD
Phase 2 Randomized Trial. Ophthalmology. 2019 Aug;126(8):1155-70.

81 Wykoff CC, Khurana RN, Lampen SI, Noronha G, Brown DM, Ou WC, et al.; HULK Study Group. Suprachoroidal Triamcinolone Acetonide for Diabetic Macular Edema: the HULK Trial. Ophthalmol Retina. 2018 Aug; 2(8):874-7.

82 Carnevali A, Sacconi R, Corbelli E, Tomasso L, Querques L, Zerbini G, et al. Optical coherence tomography angiography analysis of retinal vascular plexuses and choriocapillaris in patients with type 1 diabetes without diabetic retinopathy. Acta Diabetol. 2017 Jul;54(7): 695-702.

83 de Carlo TE, Chin AT, Bonini Filho MA, Adhi M, Branchini L, Salz DA, et al. Detection of Microvascular Changes in Eyes of Patients with Diabetes but Not Clinical Diabetic Retinopathy Using Optical Coherence Tomography Angiography. Retina. 2015 Nov;35(11): 2364-70. 